\title{
DEMARCAÇÕES HISTÓRICAS SOBRE A POLÍTICA DE ASSISTÊNCIA ESTUDANTIL NO BRASIL
}

\author{
Adão Rogério Xavier Silval \\ Mark Clark Assen de Carvalho2
}

\begin{abstract}
RESUMO
O estudo tem por objetivo situar questões que contribuem para demarcar a configuração que a política de Assistência Estudantil (AE), como política pública, vem assumindo no Brasil, no caso da Educação Superior. Para tanto, utilizou-se a análise de documentos e revisão de literatura, especialmente, a proposta apresentada por Kowalski (2012), cuja configuração é delineada em três fases. Como resultado da pesquisa, aponta-se que a primeira fase atravessou o período de criação das primeiras universidades brasileiras até a definição dos primeiros instrumentos da institucionalização da política educacional, momento marcado pelo caráter pontual das iniciativas, dado o atendimento único e exclusivo da elite brasileira que, notadamente, usufruía do acesso ao ensino superior de forma privilegiada. A segunda fase materializou-se em um cenário social no qual se tinha uma predisposição para incluir os estudantes nos programas assistenciais, cuja demanda estava intrinsicamente ligada ao processo de democratização e expansão de vagas na educação superior. Observa-se, no entanto, que, nos instrumentos legais, inexistia a designação de recursos financeiros para o custeio dos programas. Por fim, a terceira fase inicia-se a partir da execução do Programa de Apoio a Planos de Reestruturação e Expansão das Universidades Federais (REUNI) nos anos de 2007, e estende-se até os dias atuais, quando se tem, propriamente, o marco da institucionalização da política pública de assistência estudantil, com a edição da Portaria Normativa $n^{\circ}$ 39, de 2007 e, posteriormente, do Decreto Lei do Programa Nacional de Assistência Estudantil (PNAES) nº 7.234, de 2010.
\end{abstract}

Palavras-chave: Política de Assistência Estudantil. PNAES. Acesso e Permanência.

\section{HISTORICAL DEMARCATIONS ON THE STUDENT ASSISTANCE POLICY IN BRAZIL}

\begin{abstract}
This study aims to situate issues that contribute to demarcate the unfolding of Student Assistance policy in Higher Education in Brazil. To that end, it was used document analysis and literature review, especially the proposal presented by

\footnotetext{
${ }^{1}$ Mestre em Educação (UFAC). Membro do Núcleo de Estudos e Pesquisas em Política Educacional, Gestão e Financiamento da Educação da Universidade Federal do Acre (UFAC), Rio Branco, Acre, Brasil. ORCID iD: https://orcid.org/0000-0003-0277-3392. E-mail: adaorxs@gmail.com

${ }^{2}$ Doutor em Educação (PUC-SP). Professor Titular da Universidade Federal do Acre (UFAC) e Professor Permanente do Programa de Pós-Graduação em Educação da UFAC e do Doutorado em Rede/EDUCANORTE. Bolsista Capes Programa Nacional de Cooperação Acadêmica/Procad Amazônia UFPR/UFPA/UFAC. ORCID iD: https://orcid.org/0000-0003-36389719. E-mail: markassen@yahoo.com.br
} 
Kowalski (2012), whose configuration is outlined in three phases. The results indicate that the first phase went through the period of creation of the first Brazilian universities until the definition of the first instruments for the institutionalization of educational policy, a moment marked by the punctual character of the initiatives, given the unique and exclusive service of the Brazilian elite that notably enjoyed privileged access to higher education. The second phase materialized in a social scenario in which there was a predisposition to include students in assistance programs, whose demand was intrinsically linked to the process of democratization and expansion of places in higher education. It is observed, however, that, in the legal instruments, there was no designation of financial resources to fund the programs. Finally, the third phase begins with the execution of the Program of Support for Plans of Restructuring and Expansion of Federal Universities in the 2007s, and extends to the present day, when there is, properly, the landmark of the institutionalization of the public policy of student assistance through the Normative Ordinance MEC No. 39, issued in 2007 and, later, the Decree No. 7.234, issued in 2010, which established the National Program of Student Assistance, known as PNAES.

Keywords: Student Assistance Policy. PNAES. Access and Permanence.

\section{DEMARCACIONES HISTÓRICAS SOBRE LA POLÍTICA DE ASISTENCIA ESTUDIANTIL EN BRASIL}

\section{RESUMEN}

El estudio tiene como objetivo situar los problemas que contribuyen a demarcar la configuración que la política de Asistencia Estudiantil (AE), como política pública, ha estado asumiendo en Brasil, en el caso de la Educación Superior. Para ello, utilizamos el análisis de documentos y la revisión de literatura, especialmente la propuesta presentada por Kowalski (2012), cuya configuración se describe en tres fases. Como resultado de la investigación, se señala que la primera fase pasó por el período de creación de las primeras universidades brasileñas hasta la definición de los primeros instrumentos para la institucionalización de la política educativa; un momento marcado por el carácter puntual de las iniciativas, dado el servicio único y exclusivo de la élite brasileña que, en particular, disfrutaban de un acceso privilegiado a la educación superior. La segunda fase se materializó en un escenario social en el que había una predisposición a incluir a los estudiantes en los programas de asistencia, cuya demanda estaba intrínsecamente vinculada al proceso de democratización y expansión de lugares en la educación superior. Sin embargo, se observa que, en los instrumentos legales, no se designaron recursos financieros para financiar los programas. Finalmente, la tercera fase comienza con la ejecución del Programa de Apoyo a los Planes de Expansión y Reestructuración de la Universidad Federal (REUNI) en 2007, y se extiende hasta el día de hoy, cuando existe, adecuadamente, el hito de la institucionalización de la política pública de asistencia al alumno, con la edición de la Ordenanza Normativa n 39, de 2007 y, posteriormente, del Decreto Ley del Programa Nacional de Asistencia al Alumno (PNAES) n 7.234, de 2010.

Palabras clave: Política de Asistencia al Estudiante. PNAES. Acceso y Permanencia. 


\section{AS FASES HISTÓRICAS DA ASSISTÊNCIA ESTUDANTIL COMO POLÍTICA PÚBLICA NA EDUCAÇÃO SUPERIOR NO BRASIL}

No exercício da revisão de literatura, percebeu-se que, quando se trata da perspectiva histórica da temática de Política de Assistência Estudantil no Brasil, aparece, com certa frequência ${ }^{3}$, a referência ao estudo realizado por Kowalski (2012) em sua tese de doutoramento. A autora apresenta uma síntese histórica da constituição da assistência estudantil como política de educação superior brasileira, conjugando-a ao cenário da educação superior do país. De tal modo, identifica e categoriza o seu desenvolvimento em três fases, conforme serão sintetizadas nas próximas seções.

\section{A primeira fase da política de assistência estudantil}

Kowalski (2012) destaca que a primeira fase da política de assistência estudantil ocorreu em um período no qual o acesso à educação superior era restrito e distinto para poucos, isto é, encontrava-se concentrado nas mãos da elite financeira do país, visto que esta dispunha dos meios para manutenção de sua trajetória acadêmica universitária, em alguns casos, podendo optar, até mesmo, por estudar em instituições de ensino superior fora do país.

Nesse cenário é que se compõe a primeira ação de assistência estudantil promovida pelo Estado brasileiro, especificamente, no governo de Washington Luís (1926-1930) que, em 1928, incentivou a construção da Casa do Estudante Brasileiro situada em Paris, colaborando com os recursos necessários para edificação das estruturas, assim como para a manutenção da casa e dos alunos. Logo, "isso vem demonstrar que a assistência estudantil, nesse período histórico, estava voltada para o atendimento das necessidades dos filhos da elite brasileira, já que era esse perfil que tinha acesso ao ensino superior [...]" (KOWALSKI, 2012, p. 85).

\footnotetext{
${ }^{3}$ Xavier Silva (2019); Santos (2018); Garcia (2018); Motta (2017); Santos (2017).
} 
Passados dois anos da primeira ação de assistência estudantil, no início da década de 1930, na gestão do então Governo Provisório de Getúlio Vargas (1930-1934), ocorreu a promulgação, por força da aprovação da Reforma Francisco Campos, do Decreto $n^{\circ}$ 19.851/1931, que tratava do Estatuto da Organização das Universidades Brasileiras. Tal documento buscava materializar uma reforma no ensino superior, estabelecendo parâmetros para a organização didática e administrativa do regime universitário no Brasil.

A partir desse instrumento, despontou-se a possibilidade de participação consultiva e deliberativa dos estudantes nos assuntos da universidade, por meio da representação do Diretório Central dos Estudantes (DCE) no Conselho Universitário. Nesse cenário, teve-se uma participação mais efetiva dos discentes nos assuntos da universidade. Vale lembrar o apoio dado pelos Diretórios Acadêmicos (DA) que, unidos ao DCE, incumbiam-se de criar estratégias para responder às demandas/necessidades estudantis. Aqui, "começou-se a vislumbrar a regulamentação da assistência estudantil nas universidades" (KOWALSKI, 2012, p. 86).

Para além disso, as medidas de providência e beneficência estudantil, incluindo concessão de bolsas de estudos, estavam condicionadas ao entendimento da Sociedade dos Professores Universitários e do Diretório Central Estudantil, tendo em vista a atenção rigorosa do critério ${ }^{4}$ de justiça e de oportunidade.

Ainda no contexto da década de 1930, inaugurou-se a Casa do Estudante do Brasil, localizada na cidade do Rio de Janeiro, que contava com grandes doações governamentais. O prédio dispunha de três andares, sendo que, em um deles, localizava-se o restaurante popular estudantil.

\footnotetext{
4 "Esses critérios eram embasados nos méritos de cada um sendo que, no caso de pobreza, era preciso comprovar sua situação através da "declaração de pobreza" fornecida por algum instituto assistencial, bem como era observado se o comportamento do sujeito condizia com a pobreza que declarava. Caso ela fosse confirmada, ele se tornava merecedor da bolsa" (FÁVERO, 1980 citado por KOWALSKI, 2012 p. 86).
} 
Com a promulgação da Constituição Federal de 1934, visualizou-se uma investida oficial em direção à institucionalização da assistência estudantil, cuja referência específica está expressa no artigo de $n^{\circ} 157$ e seus respectivos parágrafos. Este dispõe que a União, os Estados e o Distrito Federal ficarão incumbidos de reservar uma parte dos seus patrimônios territoriais e da formação de fundos para a educação, sendo que, desses fundos, parte deverá ser aplicada em auxílios a alunos necessitados, mediante fornecimento gratuito de material escolar, bolsas de estudo, assistência alimentar, dentária e médica, e para vilegiaturas.

Em 1937, o governo, por intermédio do Ministério da Educação e Saúde, apoia a criação da União Nacional dos Estudantes (UNE). Sobre essa questão, Kowalski (2012) aponta que, talvez, essa estratégia de apoio tivesse a intencionalidade de consubstanciar uma instituição de representatividade estudantil despolitizada, isto é, alinhada aos seus interesses. Para tanto, propõe a Casa do Estudante do Brasil como sede administrativa e responsável para promoção de assistência jurídica, bolsas, empregos, biblioteca, saúde e residência.

Havia, também, uma proposta encabeçada pelos estudantes que não chegou a ser aprovada. Esta versava sobre a requisição de uma universidade mais aberta, com diminuição das taxas elevadas, as quais acabavam por selecionar o acadêmico pelo nível de renda. Desse modo, no ano de 1938, no II Congresso Nacional dos Estudantes, as acentuadas diferenças de ideias acabaram por concretizar o rompimento da ligação da UNE com a Casa do Estudante do Brasil.

Kowalski (2012) explica que é nesse contexto histórico que ocorrerá a implementação de instituições de ensino superior sob o status de universidade, nas cidades de São Paulo, Rio de Janeiro e Rio Grande do Sul, tendência que se seguiu, por volta da década de 1940, em outros estados, assim como a abertura das primeiras Universidades Católicas (PUC).

A partir da Constituição Federal de 1946, a assistência estudantil passou a ser garantida em caráter obrigatório para todos os níveis de ensino. Conforme consta no Capítulo II - Da Educação e da Cultura, artigo n 172 , 
"Cada sistema de ensino terá obrigatoriamente serviços de assistência educacional que assegurem aos alunos necessitados condições de eficiência escolar" (BRASIL, 1946).

Nesse mesmo ano, teve-se a promulgação do Decreto 20.302/1946, que tratava da aprovação dos Regimentos das Diretorias do Ensino Superior, Ensino Secundário, Ensino Comercial e Ensino Industrial, de tutela do Ministério da Educação e Saúde.

Nesse dispositivo, encontra-se, no Capítulo III, da Competência dos Órgãos, o artigo de n 8, intitulado "A Seção de Orientação e Assistência", que destaca as seguintes competências:

I - Promover a execução dos preceitos legais referentes à orientação educacional e fiscalizá-la;

II - Manter organizado um plano de assistência médico-social a alunos, estudando problemas com tal assistência relacionados;

III - estimular a organização de caixas escolares, associações literárias e desportivas, jornais, revistas e demais trabalhos complementares da educação dos alunos;

IV - Elaborar planos para concessão de bolsas de estudos a alunos e controlar a aplicação das mesmas;

$\checkmark$ - Estudar os casos de admissão gratuita de estudantes pobres nos estabelecimentos equiparados ou reconhecidos, bem como os de aquisição de uniforme e material escolar para os mesmos (BRASIL, 1946).

Após 15 anos de vigência da Carta Magna de 1946 e outros decretos incidindo nas questões sobre a educação nacional, em 20 de dezembro de 1961 houve a promulgação da Lei no 4.024, primeira Lei de Diretrizes e Bases da Educação Nacional (LDB). No que tange aos aspectos relativos à assistência estudantil constantes nesse marco legal, são dedicados dois artigos no Título XI: "Da Assistência Social Escolar". Trata-se, respectivamente, dos artigos de números 90 e 91 destacados in verbis:

Art. 90. Em cooperação com outros órgãos ou não, incumbe aos sistemas de ensino, técnica e administrativamente, prover, bem como orientar, fiscalizar e estimular os serviços de assistência social, médico-odontológico e de enfermagem aos alunos.

Art. 91. A assistência social escolar será prestada nas escolas, sob a orientação dos respectivos diretores, através de serviços que atendam ao tratamento dos casos individuais, à aplicação de 
técnicas de grupo e à organização social da comunidade (BRASIL, $1961)$.

É importante sinalizar que tais avanços se nutriram, em significativa parte, da organização, atuação e presença da UNE que, no contexto posto, compartilhava de um consensual levante em prol da Reforma Universitária. Para tanto, consta que foram realizados alguns seminários nacionais em defesa dos direitos estudantis. Dentre esses encontros, merece destaque o Seminário Nacional de Reforma Universitária, de maio de 1961, organizado na cidade de Salvador (BA), cujo resultado fora expresso no documento "Declaração da Bahia" que, em síntese, "solicitava que as universidades fossem um espaço pluralizado, por meio da criação de cursos acessíveis para todos" (KOWALSKI, 2012, p. 89).

Kowalski (2012) indica que, nesse período histórico, os militares revezaram-se no poder e na manutenção da repressão social e política. Assim, as legislações, tanto em sua constituição quanto na sua implementação, foram sofrendo sabotagens. Nessa conjuntura, a reforma universitária de 1968 foi regulamentada por força da aprovação da Lei $n^{\circ}$ 5.540/1968, que veio significar uma "anti-reforma, na qual um dos elementos atacados foram os estudantes, os jovens, os professores, críticos e militares" (FERNANDES, 1989, citado por KOWALSKI, 2012, p. 91).

No que se refere aos aspectos acadêmicos,

[...] a reforma universitária propunha a indissociabilidade entre a pesquisa e o ensino, cujo principal objetivo era que a educação superior se modernizasse. Também foi estabelecido que o corpo discente tivesse direito à representação, através de voto, nos colegiados das universidades e estabelecimentos isolados e nas comissões dos estatutos e dos regimentos. Ainda na Lei da reforma universitária de 1968, o artigo 40 estabelecia que as atividades de extensão proporcionassem aos estudantes uma maior participação no desenvolvimento da vida da comunidade. Outro mote da ditadura militar foi de: "inundar a universidade. Simulando democratizar as oportunidades educacionais no nível do ensino de terceiro grau, ela ampliou as vagas para sufocar a rebeldia dos jovens e expandir a rede do ensino particular" (FERNANDES, 1989, p.106). A prova disso é que, após o ano de 1968, houve um crescimento no número de matrículas no ensino superior de $879 \%$ entre os anos de 1970 e 2004 (BRASIL, INEP, 2006) que, beneficiou 
principalmente a classe média, atingindo alguns poucos segmentos da sociedade sem tradição no sistema (KOWALSKI, 2012, p. 91).

Nesse sentido, tal expansão imprimia preceitos do financiamento da educação superior que se revelavam como um componente desfavorável introduzido nas universidades, visto que, nessa composição, a educação superior redimensionava-se a título de mercadoria.

Por volta dos anos de 1970, fora criado o Departamento de Assistência ao Estudante (DAE), tal iniciativa do governo federal ficou vinculada ao Ministério da Educação (MEC). O departamento objetivava assegurar ações de assistência estudantil para graduandos em nível nacional, especialmente, assistência médico-odontológica, moradia, alimentação. Contudo, este foi desativado nas administrações posteriores.

A partir do exposto, considera-se que a primeira fase da política de assistência estudantil ocorreu desde a abertura das primeiras universidades no Brasil até a formulação dos primeiros dispositivos de regulamentação da política de educação. Depreende-se, então, que a política de assistência estudantil se efetivou em um cenário no qual a educação superior buscava se expandir e se consolidar como nível de ensino em meio às tendências e interesses políticos vigentes no período, acerca de sua importância e prioridades.

Reitera-se que, nesse momento histórico, o acesso à educação superior era restrito e distinto para poucos, isto é, encontrava-se fortemente concentrado nas mãos das classes mais abastadas, razão pela qual é plenamente aceitável a ideia de que a assistência estudantil atendia a uma especificidade de caráter pontual, dado o atendimento exclusivo a um tipo determinado de perfil do público que acessava o ensino superior à época.

Nos primeiros anos da década de 1980, as ações desenvolvidas pelo governo no âmbito da política de assistência estudantil tiveram maior ênfase nos antigos ensinos de $1^{\circ}$ e $2^{\circ}$ graus, hoje, Ensinos Fundamental e Médio, conforme nomenclatura definida pela atual LDB.

Naquele contexto, a Fundação de Assistência ao Estudante, vinculada ao MEC, executava ações na educação pré-escolar e de $1^{\circ}$ e $2^{\circ}$ graus 
somente. Ainda nessa década, devido à insustentabilidade do regime civilmilitar, o Brasil movimentava-se em favor da redemocratização social e política, em direção a uma nova constituição, uma nova república. Será, portanto, esse cenário que irá configurar a segunda fase da política de assistência estudantil.

\section{A segunda fase da política de assistência estudantil}

A segunda fase da política de assistência estudantil efetivou-se em um cenário marcado pelas consequências históricas e sociais oriundas do regime ditatorial civil/militar, pois, ainda que se tivesse uma democracia vigente em vias de consolidação, os problemas no campo da educação superior, como, por exemplo, a democratização do acesso e permanência, continuavam latentes. Assim, em um cenário de arenas de disputas sociais, convergia um sentimento de mudanças na configuração política no sentido da criação e fortalecimento de novas políticas públicas educacionais.

Importante situar que, nesse período, as discussões sobre o acesso e permanência passaram a ser vigorosamente realizadas nos Encontros Nacionais de Pró-Reitores de Assuntos Comunitários/Estudantis, fomentadas pela Associação Nacional dos Dirigentes das Instituições Federais de Ensino Superior (ANDIFES). Esses ambientes abertos para troca de ideias e experiências foram fundamentais para a criação, em 1987, do Fórum Nacional de Pró-Reitores de Assuntos Comunitários e Estudantis (FONAPRACE), cuja pauta central era a busca por mecanismos para viabilizar a redemocratização do acesso ao ensino superior, sobretudo, com a incorporação de estudantes de baixa renda nas IFES, com condições reais de permanência.

Nessa perspectiva, o estudo de Kowalski (2012) aponta, ainda, que:

Essas discussões ganharam eco com a promulgação da Constituição Federal de 1988, cuja finalidade era, além de buscar a garantia da efetividade dos direitos fundamentais e a prevalência dos princípios democráticos, também contemplavam o processo de redemocratização da educação, mediante a universalização do acesso e a gestão democrática, centrada na formação do cidadão. 
Embora esse documento não abordasse especificamente a educação superior é a partir dele que se começam a aprofundar as discussões referentes ao acesso e à permanência nas universidades (KOWALSKI, 2012, p. 93).

Todavia, sabe-se que as chamadas arenas sociais de disputas são movidas por interesses contraditórios. Assim, na década de 1990, teve-se o registro nacional de uma certa limitação dos recursos financeiros para as IFES, em especial, para o financiamento da assistência estudantil. Diferentemente da fase anterior, na segunda fase, durante o período da década de 1990, não se tem um documento oficial indicando aporte financeiro para manutenção de programas socioeducativos.

Essa constatação agrava-se ainda mais quando se toma, por exemplo, a referência constante no artigo 71, inciso IV, da Lei no 9394, atual LDB, promulgada em 1996:

Art. 71. Não constituirão despesas de manutenção e desenvolvimento do ensino aquelas realizadas com: (...)

IV - Programas suplementares de alimentação, assistência médicoodontológica, farmacêutica e psicológica, e outras formas de assistência social;

(...) (BRASIL, 1996).

Nessa linha de argumentação, evidencia-se a negação em relação à "desresponsabilidade do Estado com o financiamento à assistência estudantil" (KOWALSKI, 2012, p. 94), sendo que, no cenário experienciado, verificou-se um decréscimo gradual nas questões de financiamento e orçamento das IFES. De certo, não foi somente a assistência estudantil que se encontrou em cheque, mas a própria manutenção do tripé - ensino, pesquisa e extensão - das universidades brasileiras.

Para se ter uma melhor noção dessa situação, de 1995 a 2003, o percentual de recursos financeiros públicos destinados às IFES, premissa vital para os investimentos de infraestrutura e manutenção do quadro pessoal, diminuíram em relação ao Produto Interno Bruto (PIB), de 0,81\% para 0,54\% ($33,3 \%$ ), em relação ao Fundo Público Federal (FPF), de 5,12\% para 3,02\% (- 
$41 \%)$, em relação aos Impostos Federais (IF), de $11,2 \%$ para $7,3 \%(-34,8 \%)$ (SGUISSARDI, 2014).

Corroboram com essa afirmação os dados da ANDIFES, à medida que indicam que, no ano de 1994, as IFES dispunham de um quadro pessoal de 45.243 professores e de 71.408 servidores técnico-administrativos. Já nos anos de 1997, esse quadro passou para 42.227 servidores, de modo que os déficits acumulados representavam 3.016 professores e 9.981 servidores. Nesse cenário, os sucessivos cortes de verbas e de pessoal intensificaram a situação de caos em praticamente todas as universidades públicas (LAMPERT, 2006).

No ano de 1998, a Organização das Nações Unidas para a Educação, a Ciência e a Cultura (UNESCO) do Brasil, tomada pela Conferência Mundial sobre a Educação Superior, realizada em Paris, empenha-se em reverberar o documento Declaração Mundial sobre Educação Superior no Século XXI.

Esse documento traz, na letra do seu artigo $3^{\circ}$, intitulado "Igualdade de acesso", a consideração de que os grupos menos favorecidos los povos indígenas, os membros de minorias culturais e linguísticas) deveriam dispor de uma assistência material especial e de soluções educacionais que contribuíssem para a superação dos obstáculos no percurso acadêmico, no que tange ao acesso e à permanência destes.

No ano subsequente, em 1999, o governo, por meio do Ministério da Educação (MEC), inclinado pelas questões do "acesso e permanência ao ensino superior", cria o Fundo de Financiamento ao Estudante do Ensino Superior (FIES). Tal fundo tem por objetivo financiar a graduação dos estudantes matriculados nas instituições privadas, relegando a um plano inferior as questões do acesso e permanência nas IFES públicas.

A aprovação do Plano Nacional de Educação (PNE), através Lei $n^{\circ}$ 10.172, de 2001, diga-se de passagem, constituiu-se na contramão do que se esperava de um plano nacional, na medida em que apresenta uma

Completa oposição ao PNE elaborado por um amplo conjunto de entidades ligadas à educação, reafirmando a transferência de responsabilidade do Poder Público para a sociedade no 
financiamento da educação e sua concepção de gestão educacional com ênfase na informatização, controle e gerenciamento profissional. Em relação à educação superior, reafirma sua política de diversificação das IES e de suas fontes de financiamento (LIMA, 2007, p.143).

Assim, devido à forte reivindicação dos movimentos sociais, relativa às questões da assistência estudantil, conseguiu-se, ao menos, pactuar o seguinte:

33. Estimular as instituições de ensino superior a identificar, na educação básica, estudantes com altas habilidades intelectuais, nos estratos de renda mais baixa, com vistas a oferecer bolsas de estudo e apoio ao prosseguimento dos estudos.

34. Estimular a adoção, pelas instituições públicas, de programas de assistência estudantil, tais como bolsa-trabalho ou outros destinados apoiar os estudantes carentes que demonstrem bom desempenho acadêmico (BRASIL, 2001).

Todavia, percebe-se que o governo federal deu continuidade à sua agenda de atenção e proteção à iniciativa privada no ensino superior, criando, no ano de 2004, o Programa Universidade para Todos (ProUni), instituindo pela Lei $n^{\circ} 11.906 / 2005$, que se propunha a conceder bolsas de estudos integrais e parciais aos estudantes da graduação e de cursos sequenciais de formação específica de instituições privadas. Esse programa, a exemplo do FIES, volta sua atenção somente a uma "assistência estudantil" no aspecto da manutenção das mensalidades, escanteando, de forma geral, a sustentação desses alunos nos aspectos mais amplos da trajetória acadêmica.

Considerando o exposto acima, a segunda fase da assistência deu-se em um cenário onde a conjuntura sociopolítica apontava para um maior enfoque das políticas sociais, dada a abertura democrática. Nota-se, contudo, uma forte tendência à democratização e expansão da educação superior por via de programas assistenciais que fomentaram, principalmente, a iniciativa privada, no que se refere a esse processo de inclusão.

Ainda que não tenha ocorrido, nessa fase, uma agenda governamental dedicada às questões de assistência estudantil, voltada para a educação superior pública, o desenvolvimento dos programas criou 
condições para que uma significativa parcela de sujeitos socialmente e historicamente excluídos desse nível de ensino pudessem acessá-lo. Cumpre ressaltar que, nesse período, a legislação vigente não abarcava e tampouco direcionava recursos para o custeio direto a programas socioeducativos, isso caso se leve "ao pé da letra" o que está expresso no artigo 71, inciso IV da LDB de 1996.

Entretanto, tais ações, voltadas à iniciativa privada, acabaram por ratificar ainda mais a premência da assistência estudantil em uma agenda pública fortemente marcada e decorrente do próprio esforço governamental para ampliar o acesso ao ensino superior. Nessa direção é que se constituirá a terceira fase da política de assistência estudantil no Brasil.

\section{A terceira fase da assistência estudantil: em vigor até ulterior deliberação!}

Conforme demonstrou-se, a segunda fase da política de assistência estudantil efetivou-se em um cenário marcado pelas consequências históricas e sociais oriundas do regime ditatorial civil/militar, pois, ainda que se tivesse uma democracia em vias de consolidação, os problemas no campo da educação em geral, e da educação superior, em particular, continuavam evidentes e clamavam por políticas mais contundentes. Assim, nas arenas de disputas sociais, convergia um sentimento de mudanças para que fossem instituídas e fortalecidas novas políticas públicas, com relevo para as da educação.

Por seguinte, a terceira fase (fase atual) da política de assistência estudantil engendrou-se a partir da promulgação do Decreto $n^{\circ} 6.096$, de 2007, que veio a instituir o Programa de Apoio ao Plano de Reestruturação e Expansão das Universidades Federais (REUNI), cuja intencionalidade era a criação de condições para ampliação do acesso e garantias de permanência aos estudantes no Ensino Superior no nível de graduação, bem como o melhoramento e aproveitamento da estrutura física e de recursos humanos existentes nas universidades federais. 
Para tanto, indica um investimento, de forma gradativa, no montante de $R \$ 2$ bilhões, a serem acrescidos ao orçamento de custeio e pessoal das IFES no período compreendido entre os anos de 2008 e 2012. Esse aporte financeiro destinar-se-ia à construção e readequação de infraestrutura e equipamentos, compra de bens e serviços necessários, além de despesas de custeio e pessoal associadas à expansão das atividades decorrentes do plano, dentre as quais estava incluído o incentivo para o aumento de vagas de ingresso nos cursos de graduação ofertados no período noturno. Em linhas gerais, o REUNI inscreve-se como subsídio para uma série de ações delineadas que acompanham os documentos anteriores (BRASIL, 2007).

Essas novas circunstancias, por certo, realçaram ainda mais a necessidade de assegurar condições efetivas para que os acadêmicos permanecessem e concluíssem seus cursos de graduação dentro dos prazos mínimos. Em meio a toda essa movimentação que considerou os documentos editados na gestão do governo federal, traçada até aqui, fato é que, pela primeira vez, teve-se em um documento oficial - REUNI - a menção ao Plano Nacional de Assistência Estudantil (PNAES), isto é, o Estado começa a sinalizar com a ideia de consolidar um plano nacional de assistência estudantil.

A partir dessas considerações, pode-se reconhecer, então, que o PNAES aparece como instrumento de consolidação do REUNI - conforme apresenta o Plano de Desenvolvimento da Educação (PDE ${ }^{5}$ ). Por seu turno, o REUNI vislumbrava a anunciada expansão do acesso ao ensino superior com indicativo do aumento expressivo de estudantes de camadas sociais de menor renda. Assim, caberia ao PNAES endossar as perspectivas que ensejavam a ampliação do acesso, bem como sustentar a adoção de políticas afirmativas que dessem sustentação a essa ampliação.

\footnotetext{
5 "Lançado pelo governo federal em abril de 2007, o PDE prevê um aporte maior de recursos para a manutenção e desenvolvimento da educação nos próximos dez anos na ordem de $\mathrm{R} \$ 8$ bilhões de reais. O Plano tem como objetivo central melhorar a qualidade da educação pública no Brasil através de um conjunto de medidas que atinge todos os níveis e etapas da educação nacional" (DANTES; SOUZA JUNIOR, 2009, p. 07).
} 
Nesse ambiente, o governo federal aprovou o Plano Nacional de Assistência Estudantil (PNAES) no final do ano de 2007, instituindo-o através da Portaria Normativa $n^{\circ} 39$ do Ministério da Educação e Cultura. Vale assinalar que a proposição textual do documento PNAES foi uma iniciativa do FONAPRACE que, ao longo dos últimos vinte anos, perseverou, junto aos movimentos sociais, em pautas nacionais. Como exemplo, a questão da importância da assistência estudantil para o desenvolvimento da vida e do percurso acadêmico e de sua relevância para consolidação da expansão e democratização, acesso e permanência nesse nível de ensino aos estudantes oriundos das classes sociais de baixa renda.

Nos termos do PNAES, a Assistência Estudantil (AE) vinculou-se ao desenvolvimento das atividades de ensino, pesquisa e extensão. Destina-se a estudantes matriculados em cursos de graduação presencial, selecionados a partir de critérios socioeconômicos e deveria, no desenvolvimento das ações, atender, prioritariamente, as seguintes áreas: I - moradia estudantil; II - alimentação; III - transporte; IV - assistência à saúde; V - inclusão digital; VI cultura; VII - esporte; VIII - creche; e IX - apoio pedagógico (BRASIL, 2007a).

O avanço da institucionalização da AE por meio de uma Portaria Normativa, ainda que relevante, porém tratada como investimento, não parecia ser suficiente aos formuladores da concepção de Assistência Estudantil. Assim, a $46^{a}$ Reunião do FONAPRACE, realizada em outubro de 2009, em Belo Horizonte/MG, considerou como meta prioritária a consolidação do PNAES em uma lei federal. No encontro,

[...] refletiu-se sobre a necessidade da construção de uma matriz orçamentária que pudesse garantir a continuidade dos recursos específicos à Assistência Estudantil. Assim, definiu-se que a Matriz de distribuição dos recursos PNAES deveria ser revista em função das exigências sociais e políticas, a fim de garantir a permanência dos estudantes em condições de vulnerabilidade social e econômica (FONAPRACE, 2012, p. 33).

O desvelar dessa questão concretizou-se na elaboração de um documento deliberativo formulado na $47^{a}$ Reunião do FONAPRACE, realizada em maio de 2010, em Brasília/DF. O referido documento fora 
encaminhado à ANDIFES, conforme Ofício n 19/FONAPRACE, datado de 13 maio de 2010, cujo conteúdo, aqui, interessa saber:

1. Reafirmação da importância do Programa Nacional de Assistência - PNAES (Portaria Normativa $n^{\circ} 39$, de 12 de dezembro de 2007), defendendo sua continuidade e seu direcionamento para uma POLÍTICA DE ESTADO, haja vista o papel relevante que essa política cumpre no processo educativo e formativo no ambiente universitário (OFíCIO 19/FONAPRACE, 2010 citado por FONAPRACE, 2012, p. 35).

Sem tardar, iniciaram-se, junto às instâncias de governo, as tratativas em relação à demanda da política. Assim, após três anos de existência, o PNAES deixa o status de Portaria Normativa para ser o Decreto Lei $n^{0} 7.234$, de 19 julho de 2010. Paula (2017) observa a importância da institucionalização em lei da portaria, dado o compromisso legal do governo com a efetivação do repasse de recursos financeiros às IFES.

Vale sinalizar que, antes da institucionalização do PNAES, os financiamentos das ações vinculadas à $A E$ dependiam da sensibilidade da gestão das IFES com a temática, bem como da mobilização dos DCE's e Centros Acadêmicos (CA), uma vez que não existia repasse de recursos financeiros específicos para tal.

Composto por nove artigos, o Decreto Lei $n^{\circ} 7.234 / 2010$ define suas finalidades e seus objetivos nos dois primeiros dispositivos, como se verifica abaixo:

Art. $1^{\circ} \mathrm{O}$ Programa Nacional de Assistência Estudantil - PNAES, executado no âmbito do Ministério da Educação, tem como finalidade ampliar as condições de permanência dos jovens na educação superior pública federal ampliar as condições de permanência dos jovens na educação superior pública federal.

Art. $2^{\circ}$ São objetivos do PNAES:

I-Democratizar as condições de permanência dos jovens na educação superior pública federal; II-minimizar os efeitos das desigualdades sociais e regionais na permanência e conclusão da educação superior; III - reduzir as taxas de retenção e evasão; e IV contribuir para a promoção da inclusão social pela educação (BRASIL, 2010). 
No que se refere ao desenvolvimento das ações da $A E$, vinculadas ao Decreto Lei PNAES, além de permanecerem as áreas já previstas na Portaria Normativa anterior, inclui-se uma nova ação/área, descrita no item X do parágrafo $1^{\circ}$ do Art. $3^{\circ}$, a saber: " $X$ - acesso, participação e aprendizagem de estudantes com deficiência, transtornos globais do desenvolvimento e altas habilidades e superdotação" (BRASIL, 2010).

Outro elemento novo foi a ampliação das instituições executoras da AE no âmbito no PNAES. Com a promulgação da Lei n 11.892, de 29 de dezembro de 2008, que instituiu a Rede Federal de Educação Profissional, Científica e Tecnológica, foram criados os Institutos Federais de Educação, Ciência e Tecnologia, agora, também incluídos como executores da AE pelo no Art. $4^{\circ}$ do PNAES.

Importante dizer que foi resguardada a autonomia das instituições executoras em relação aos critérios e à metodologia de seleção dos estudantes a serem beneficiados; contudo, o novo texto fixou, em seu artigo $5^{\circ}$, como público alvo prioritário do PNAES, "[...] estudantes oriundos da rede pública de educação básica ou com renda familiar per capita de até um salário mínimo e meio [...]" (BRASIL, 2010).

Em linhas bem gerais, o novo texto do PNAES apresenta-se com as mesmas finalidades e busca atingir os mesmos objetivos do PNAES instituído pela Portaria Normativa $n^{\circ} 39 / 2007$, entretanto, além da inclusão dos novos itens supracitados, o novo texto visa capitalizar as intenções da AE.

Desse modo, o que se observa é que, a partir do ano de 2008, as reivindicações dos movimentos sociais (FONAPRACE, UNE, ANDIFES, CA, dentre outros), referentes à assistência estudantil, passaram a ser atendidas com o aporte financeiro e tiveram reconhecimento legal enquanto política pública da educação. Transcorridos dois anos de sua institucionalização, o PNAES deixa de estar amparado em uma portaria normativa e passa a ter como fundamento a edição de um Decreto Lei n 7234/2010, que veio para afirmar e consolidar a assistência estudantil como política de direito, espraiando-se pelas diferentes instituições públicas federais de ensino superior. 
Ocorreu, também, a aprovação do Decreto n 7.233, de 19 de julho de 2010, que versa sobre os procedimentos orçamentários e financeiros relacionados à autonomia universitária, especialmente, no que diz respeito às mudanças de rubricas e à possibilidade de transferência de recursos de um exercício financeiro para um outro. $E$, ainda, a promulgação do Decreto $n^{\circ} 7.41630$, de dezembro de 2010, que regulamenta os artigos 10 e 12 da Lei $n^{\circ} 12.155$, de 23 de dezembro de 2009, que tratam da concessão de bolsas para desenvolvimento de atividades de ensino e extensão universitária.

Outro dispositivo importante que ancora a discussão das questões da assistência estudantil é o Projeto de Lei (PL) do Plano Nacional de Educação (PNE 2011-2020), que veio a ser aprovado somente no ano de 2014, através da Lei $n^{\circ} 13.005$, com a vigência para dez anos.

Consta na Meta 12 do PNE, no item 12.5, a atenção para:

\begin{abstract}
Ampliar as políticas de inclusão e de assistência estudantil dirigidas aos (às) estudantes de instituições públicas, bolsistas de instituições privadas de educação superior e beneficiários do Fundo de Financiamento Estudantil - FIES, de que trata a Lei no10.260, de 12 de julho de 2001, na educação superior, de modo a reduzir as desigualdades étnico-raciais e ampliar as taxas de acesso e permanência na educação superior de estudantes egressos da escola pública, afrodescendentes e indígenas e de estudantes com deficiência, transtornos globais do desenvolvimento e altas habilidades ou superdotação, de forma a apoiar seu sucesso acadêmico (BRASIL, 2014).
\end{abstract}

Diferentemente das duas fases anteriores, que não dispunham de uma regulamentação em âmbito nacional voltada exclusivamente para a assistência estudantil, a terceira e atual fase dispõe. Observa-se, nesta fase, a institucionalização do PNAES em sua forma Normativa e, posteriormente, em decreto lei, que instrumentaliza e consolida a garantia formal ao direito à assistência estudantil, possibilitando a inclusão de uma parcela da sociedade que não tinha expectativa de acesso à educação superior pública e de permanência nesta. Sua ocorrência dá-se em confluência com o período de expansão e reestruturação das IFES e segue apesar do desmonte das políticas públicas levadas a efeito pelo atual governo federal. 
Pelo exposto, depreende-se, então, que as três fases são bem distintas e suas ênfases ou prioridades denotam haver certa ruptura na concepção de assistência estudantil no âmbito da educação superior. Contudo, percebe-se uma similar continuidade que se apresenta de maneira reformulada, estando imbricada ao contexto e momento histórico vivenciado, sobretudo, no que tange às questões afetas às políticas educacionais.

Nesse sentido e como forma de demarcar alguns de seus elementos fundantes, elaborou-se um quadro síntese das respectivas fases.

QUADRO 1 - SÍNTESE DAS FASES HISTÓRICAS DA INSTITUCIONALIZAÇÃO DA POLÍTICA DE ASSISTÊNCIA ESTUDANTIL NO BRASIL (CONTINUA)

\begin{tabular}{|c|c|c|}
\hline Fases & Ambiência política, social e institucional & $\begin{array}{c}\text { Características e ênfases } \\
\text { gerais }\end{array}$ \\
\hline Primeira fase & $\begin{array}{l}1928 \text { - Construção e manutenção da } \\
\text { Casa do Estudante Brasileiro na cidade } \\
\text { de Paris/França. } \\
1930 \text { - Abertura da Casa do Estudante } \\
\text { do Brasil na cidade do Rio de Janeiro/RJ. } \\
1931 \text { - Decreto no } 19851 \text { / } 1931 \text {, Estatuto } \\
\text { da Organização das Universidades } \\
\text { Brasileiras, primeiro documento a tratar } \\
\text { da AE na educação superior. } \\
1934 \text { - Art. } 157 \text { da Constituição Federal } \\
\text { de } 1934 \text {, tem-se indicativo de fundos } \\
\text { para a AE. } \\
1937 \text { - Criação da União Nacional dos } \\
\text { Estudantes (UNE). } \\
1946 \text { - Constituição Federal de 1946, } \\
\text { subscreveu a obrigatoriedade dos } \\
\text { serviços de assistência educacional em } \\
\text { todos os níveis de ensino. } \\
1961 \text { - Art. } 90 \text { e } 91 \text { da LDB de } 1961 \\
\text { estabeleceu a promoção e o estímulo } \\
\text { dos serviços de assistência social e } \\
\text { escolar aos estudantes. } \\
1970 \text { - Criação do Departamento de } \\
\text { Assistência ao Estudante (DAE), } \\
\text { responsável por assegurar as ações de } \\
\text { AE em nível nacional. }\end{array}$ & $\begin{array}{l}\text { Caráter pontual da } \\
\text { assistência estudantil, tendo } \\
\text { em vista a atenção de } \\
\text { natureza praticamente } \\
\text { exclusiva ao atendimento } \\
\text { da elite que tinha o } \\
\text { privilégio de acessar a } \\
\text { educação superior. }\end{array}$ \\
\hline
\end{tabular}

Revista Exitus, Santarém/PA, Vol. 10, p. 01-26, e020042, 2020. 


\begin{tabular}{|c|c|c|}
\hline Segunda fase & $\begin{array}{l}1987 \text { - Criação do Fórum Nacional de } \\
\text { Pró-Reitores de Assuntos Comunitários e } \\
\text { Estudantis (FONAPRACE). } \\
1988 \text { - Constituição Federal de } 1988 \text { - } \\
\text { alargou a promoção dos direitos sociais, } \\
\text { dentre eles o direito à Educação (acesso } \\
\text { e permanência). } \\
1990 \text { - Contingenciamento dos recursos } \\
\text { financeiros voltados à assistência } \\
\text { estudantil. } \\
1996 \text { - Promulgação da Lei de Diretrizes e } \\
\text { Bases da Educação Nacional (LDB). Tal } \\
\text { documento não apresentou nenhuma } \\
\text { discussão acerca da PAE. }\end{array}$ & $\begin{array}{l}\text { Cenário social fértil da } \\
\text { abertura democrática, } \\
\text { favorecendo as discussões } \\
\text { sobre AE, as quais foram } \\
\text { fortalecidas com a criação } \\
\text { do FONAPRACE. } \\
\text { Entretendo, na década de } \\
\text { 1990, não se verifica uma } \\
\text { agenda governamental } \\
\text { pública para atendimento } \\
\text { dessa pauta, mas, sim, um } \\
\text { movimento adverso. Por } \\
\text { outro lado, houve políticas } \\
\text { assistenciais aos estudantes } \\
\text { das IES privadas. }\end{array}$ \\
\hline
\end{tabular}

Fonte: Adaptado a partir de Kowalski (2012). Elaboração dos autores.

QUADRO 1 - SÍNTESE DAS FASES HISTÓRICAS DA INSTITUCIONALIZAÇÃO DA POLÍTICA DE ASSISTEENCIA ESTUDANTIL NO BRASIL (CONCLUSÃO)

\begin{tabular}{|c|c|c|}
\hline Fases & Ambiência política, social e institucional & $\begin{array}{c}\text { Características e ênfases } \\
\text { qerais }\end{array}$ \\
\hline Segunda fase & $\begin{array}{l}1998 \text { - Declaração Mundial sobre } \\
\text { Educação Superior no Século XXI. } \\
\text { Resultado da Conferência Mundial sobre } \\
\text { a Educação Superior de Paris/França - } \\
\text { buscou em alguns aspectos promover a } \\
\text { importância de programas de } \\
\text { assistências sociais nas IFES. } \\
1999 \text { - Criação do Financiamento ao } \\
\text { Estudante do Ensino Superior (FIES), } \\
\text { suporte financeiro destinado aos } \\
\text { estudantes de graduação de baixa } \\
\text { renda matriculados em IES privadas. } \\
2001 \text { - Aprovação do PNE, no qual tem- } \\
\text { se a indicação, no item } 4.4 \text { - } \\
\text { Financiamento e Gestão da Educação } \\
\text { Superior, o estímulo à AE. } \\
2004 \text { - Criação do Programa } \\
\text { Universidade para Todos (ProUni), para } \\
\text { promover a oferta de bolsas de estudos. }\end{array}$ & $\begin{array}{l}\text { Mencionadas na página } \\
\text { anterior. }\end{array}$ \\
\hline Terceira fase & $\begin{array}{l}2007 \text { - Criação do Programa de Apoio } \\
\text { ao Plano de Reestruturação e Expansão } \\
\text { das Universidade Federais (REUNI), marco } \\
\text { para ampliação de políticas de inclusão } \\
\text { e da assistência estudantil. } \\
2007 \text { - Instituição do Programa Nacional } \\
\text { de Assistência Estudantil (PNAES) através } \\
\text { da Portaria Normativa n } 39 \text { do MEC, } \\
\text { objetivando democratizar as condições } \\
\text { de acesso e permanência aos } \\
\text { estudantes de baixa renda nos cursos } \\
\text { presenciais na IFES. } \\
2010 \text { - Elevação da Portaria Normativa no }\end{array}$ & $\begin{array}{l}\text { Nesta fase, tem-se o marco } \\
\text { da institucionalização da } \\
\text { política pública de } \\
\text { assistência estudantil, com } \\
\text { a promulgação da Portaria } \\
\text { Normativa e, } \\
\text { posteriormente, Decreto Lei } \\
\text { do Programa Nacional de } \\
\text { Assistência Estudantil } \\
\text { (PNAES) em } 2010 \text {, visando } \\
\text { ampliar as condições de } \\
\text { permanência aos } \\
\text { estudantes na educação }\end{array}$ \\
\hline
\end{tabular}

Revista Exitus, Santarém/PA, Vol. 10, p. 01-26, e020042, 2020. 


\begin{tabular}{|c|c|c|}
\hline & $\begin{array}{l}39 \text { para Decreto Lei n } 7.234 \text {; aprovação } \\
\text { do Decreto Lei n } 7.233 \text {, que trata dos } \\
\text { procedimentos orçamentários e } \\
\text { financeiros relacionados à autonomia } \\
\text { universitária; regulamentação das bolsas } \\
\text { para o desenvolvimento de ensino e } \\
\text { extensão, através do Decreto n } 7.416 \text {. } \\
2010 / 2011 \text { - Apresentação do Projeto de } \\
\text { Lei do PNE } 2011-2020, \text { cujo destaque } \\
\text { cabe à Meta 12, na qual consta a } \\
\text { consideração aos programas de } \\
\text { assistência estudantil. }\end{array}$ & superior pública federal. \\
\hline
\end{tabular}

Fonte: Adaptado a partir de Kowalski (2012). Elaboração dos autores.

A partir dessa exposição, é significativo destacar que a terceira fase projeta um cenário absolutamente distinto em relação às fases anteriores precedentes, cujo diferencial poderia ser reconhecido pela normatização e regulamentação da Política Nacional de Assistência Estudantil no âmbito das instituições públicas federais de ensino superior.

Considerando eventuais limites no processo de sua materialização, não se pode deixar de reconhecer os efeitos significativos que a adoção do PNAES passou a exercer na produção de novas condições de acesso e permanência nas IFES, seja pela mudança nas lógicas até predominantes, seja pelas concepções, seja pela adoção de novas práticas de atendimento e apoio à permanência estudantil na educação superior.

Como bem destaca Vieira e Castro (2019, p. 99) "[...] O PNAES ainda se constitui como o Programa que tem garantido a permanência de muitos estudantes que há alguns anos eram alijados do ensino superior".

Nessa nova ambiência e configuração da política de assistência estudantil, é imperioso sobrelevar que a adoção do PNAES é, indiscutivelmente, elemento de indução de criação de outras formas de acesso e de criação de condições de permanência a um determinado tipo de público histórica e socialmente excluído da possibilidade efetiva de estar na Universidade Pública. A esse grupo sempre foi negado o direito à educação superior, em um contexto social e educacional fortemente marcado pelas crescentes assimetrias e desigualdades sociais, econômicas, culturais e de formação acadêmica. 


\section{CONSIDERAÇÕES FINAIS}

Ao passo que caminhamos para a conclusão deste estudo, é pertinente considerar que observamos que a Assistência Estudantil (AE) promovida pelo Estado brasileiro para o atendimento dos estudantes de graduação do ensino superior pode ser classificada em três fases: a primeira fase corresponde ao período da criação da Casa do Estudante Brasileiro, em 1928, e estende-se até o final da década de 1970, quando se tem a criação do Departamento de Assistência ao Estudante (DAE); a segunda fase condiz com o período próximo à abertura democrática no Brasil, especificamente, a partir da criação do Fórum Nacional de Pró-Reitores de Assuntos Comunitários e Estudantis (FONAPRACE), em 1987, e se amplifica até a elaboração do Programa Universidade para Todos (ProUni), nos anos de 2004; e a terceira fase corresponde ao período que se inicia em 2007, a contar da criação do Programa de Apoio a Planos de Reestruturação e Expansão das Universidades Federais (REUNI) e estende-se até os dias atuais.

Sinaliza-se que essas ações, acima demarcadas, independente do período histórico, não se materializaram sem a manifestação de confrontos, resistências, polarizações e contradições inerentes às pautas e aos interesses que subjazem às iniciativas empreendidas pelos sujeitos envolvidos na produção desses significados. E, vale destacar, estejam esses sujeitos perfilados à negação da Assistência Estudantil como política pública ou ao seu reconhecimento como necessidade imperiosa circunscrita, também, nos domínios do direito à educação com fulcro nas melhorias das condições de acesso e permanência nas IFES brasileiras por parte de um determinado tipo de público tratado às margens desse ambiente.

Nos limites da conjuntura atual, reconhecem-se ganhos e avanços substanciais nos últimos 15 anos, em especial, aqueles referentes à institucionalização da política pública de assistência estudantil nacionalmente. Contudo, na contramão disso, tem-se a aprovação da Emenda Constitucional $n^{\circ}$ 95, de 15 de dezembro de 2016, a nomeada "Teto dos Gastos Públicos", que limita o crescimento das despesas do governo 
brasileiro durante 20 anos em serviços essenciais, como educação e saúde, por exemplo, agravada com a política de desmonte e percepção do atual presidente da república ao tratar do principal projeto político para Educação Superior brasileira, o nomeado (des) "Future-se".

Tal projeto é exposto como um "programa simples que vai dar nova dinâmica para a educação"6. De fato, trará uma nova dinâmica, sobretudo, no que se refere à concepção central do programa em propor a diminuição da participação do Estado na manutenção financeira das IFES, encabeçando uma proposta de financiamento misto com a iniciativa privada e gestão compartilhada com Organizações Sociais (OS).

Logo, acredita-se que a materialização desse projeto, nitidamente, colocará em risco o ingresso e permanência das camadas sociais historicamente excluídas do nível da educação superior.

Nesse sentido, as políticas que visam possibilitar o acesso e permanência devem ser mantidas, intensificadas, ampliadas e melhoradas, para que possam promover a inclusão daqueles que sempre foram impedidos de chegar a esse nível de ensino.

\section{REFERÊNCIAS}

BRASIL. Constituição da República dos Estados Unidos do Brasil, de 16 de julho de 1934. Disponível em:

http://www.planalto.gov.br/ccivil_03/constituicao/constituicao34.htm. Acesso em 20 de março de 2020.

BRASIL. Constituição dos Estados Unidos do Brasil, de 18 de setembro de 1946. Disponível em: http://www.planalto.gov.br/ccivil_03/Constituicao/Constituicao46.htm. Acesso em 20 de março de 2020.

BRASIL. Decreto $n^{\circ} \mathbf{2 0 . 3 0 2}$, de 2 de janeiro de 1946. Aprova os Regimentos das Diretorias do Ensino Superior, Ensino Secundário, Ensino Comercial e Ensino Industrial, do Ministério da Educação e Saúde. Disponível em: http://www2.camara.leg.br/legin/fed/decret/1940-1949/decreto-20302-2-

6 Disponível em https://exame.abril.com.br/brasil/weintraub-apresenta-projeto-parauniversidades-federais/ acesso em 20 de março de 2020. 
janeiro-1946-327736-publicacaooriginal-1-pe.html. Acesso em 20 de março de 2020.

BRASIL. Lei $n^{\circ}$ 4.024, de 20 de dezembro de 1961. Fixa as Diretrizes e Bases da Educação Nacional. Disponível em: http://www2.camara.leg.br/legin/fed/lei/1960-1969/lei-4024-20-dezembro1961-353722-publicacaooriginal-1-pl.html. Acesso em 20 de março de 2020.

BRASIL. Lei $n^{\circ}$ 6.025, de 5 de abril de 1974. Autoriza o Poder Executivo a transformar a Fundação Universidade do Acre em Fundação Universidade Federal do Acre e dá outras providências. Disponível em: https://www2.camara.leg.br/legin/fed/lei/1970-1979/lei-6025-5-abril-1974357535-publicacaooriginal-1-pl.html. Acesso em 20 de março de 2020.

BRASIL. Lei $\mathbf{n}^{\circ} \mathbf{7 4 . 7 0 6}$, de 17 de outubro de 1974. Institui a Fundação Universidade Federal do Acre, e aprova o respectivo Estatuto. Disponível em: https://www2.camara.leg.br/legin/fed/decret/1970-1979/decreto-74706-17outubro-1974-423324-publicacaooriginal-1-pe.html. Acesso em 20 de março de 2020.

BRASIL. Plano Diretor da Reforma do Aparelho do Estado. Brasília, 1995. Disponível em:

http://www.bresserpereira.org.br/Documents/MARE/PlanoDiretor/planodireto r.pdf. Acesso em 20 de março de 2020.

BRASIL. Lei $n^{\circ}$ 9.394, de 20 de dezembro de 1996. Estabelece as diretrizes e bases da educação nacional.

http://www.planalto.gov.br/ccivil_03/leis/L9394.htm. Acesso em 20 de março de 2020.

BRASIL. Lei $\mathrm{n}^{\circ}$ 11.096, de 13 de janeiro de 2005. Institui o Programa Universidade para Todos - PROUNI, regula a atuação de entidades beneficentes de assistência social no ensino superior; altera a Lei no 10.891, de 9 de julho de 2004, e dá outras providências. Disponível em: http://www.planalto.gov.br/ccivil_03/_Ato2004-2006/2005/Lei/L1 1096.htm. Acesso em 20 de março de 2020.

BRASIL. Decreto ${ }^{\circ}$ 6.096, de 24 de abril de 2007. Institui o Programa de Apoio a Planos de Reestruturação e Expansão das Universidades Federais - REUNI. Disponível em: http://www.planalto.gov.br/ccivil_03/_Ato20072010/2007/Decreto/D6096.htm. Acesso em 20 de março de 2020.

BRASIL. Portaria Normativa n 39, de 12 dez. 2007a. Institui o Programa Nacional de Assistência Estudantil - PNAES. Disponível em:

http://portal.mec.gov.br/arquivos/pdf/portaria_pnaes.pdf. Acesso em 20 de março de 2020. 
BRASIL. Decreto $n^{\circ}$ 7.234, de 19 de julho de 2010. Dispõe sobre o Programa Nacional de Assistência Estudantil - PNAES. Disponível em:

http://www.planalto.gov.br/ccivil_03/_Ato2007-

2010/2010/Decreto/D7234.htm. Acesso em 20 de março de 2020.

BRASIL. Lei n 13.005, de 25 de junho de 2014. Aprova o Plano Nacional de Educação - PNE e dá outras providências. Disponível em:

http://www2.camara.leg.br/legin/fed/lei/2014/lei-13005-25-junho-2014-

778970-publicacaooriginal-144468-pl.html. Acesso em 20 de março de 2020.

BRASIL. Emenda Constitucional N 95, de 15 de dezembro de 2016. Altera o Ato das Disposições Constitucionais Transitórias, para instituir o Novo Regime Fiscal. Disponível em:

http://www.planalto.gov.br/ccivil_03/constituicao/Emendas/Emc/emc95.htm .Acesso em 20 de março de 2020.

DANTAS, É. da S.; SOUZA JUNIOR, L. de. Na contracorrente: A política do governo Lula para a educação superior. In: Anais da $32^{a}$ Reunião Anual da Associação Nacional de Pesquisa em Educação, 2009, Caxambu - MG. Sociedade, cultura e Educação: Novas regulações. Rio de Janeiro/RJ: ANPED, 2009.

GARCIA, D. R. N. de S. A política de assistência estudantil na educação

superior: um estudo de caso no Instituto Federal de Mato Grosso do Sul - IFMS (2012-2016). Dissertação (Mestrado em Educação). Universidade Federal de Mato Grosso do Sul - UFMS, 2018.

KOWALSKI, A. V. Os (des) caminhos da política de assistência estudantil e o desafio na garantia de direitos. 179 f. Tese (Doutorado em Serviço Social). Pontifícia Universidade Católica do Rio Grande do Sul - PUCRS, 2012. LAMPERT, E. O desmonte da Universidade pública: a interface de uma ideologia. Linhas (UDESC), v. 7, p. 10-30, 2006.

LIMA, K. R. de S. Contra-reforma na educação superior: de FHC a Lula. São Paulo: Xamã, 2007.

MOTTA, T. C. Assistência Estudantil e Inclusão Social. Tese (Doutorado em Educação). Universidade Federal de Pernambuco - UFPE, 2017.

PAULA, M. de F. C. de. Políticas de democratização da educação superior brasileira: limites e desafios para a próxima década. Avaliação: Revista da avaliação da Educação Superior, v. 22, p. 301-315, 2017.

SANTOS, F. N. dos. As percepções dos sujeitos que vivenciam a assistência estudantil acerca desse direito social: um olhar a partir do IFNMG, Campus Avançado Janaúba. Dissertação (Mestrado em Educação) Universidade Estadual do Sudoeste da Bahia - UESB, 2017. 
SANTOS, E. C. dos. Política de assistência estudantil para estudantes cotistas de baixa renda na Universidade Federal do Rio Grande do SUl - UFRGS.

Dissertação (Mestrado em Educação). Universidade Federal do Rio Grande do SUl - UFRGS, 2018.

SGUISSARDI, V. Estudo Diagnóstico da Política de Expansão da (e Acesso à) Educação Superior no Brasil - 2002-2012. Brasília: Edital N. 051/2014 SESU; Projeto de Organismo Internacional - OEl; Projeto OEI/BRA/10/002, Versão revisada e corrigida em jun./2018, 2014.

VIEIRA, Pricila Lysik; MOURA CASTRO, Regina Celi Alvarenga de. Permanência e êxito acadêmico: contribuição da Política de assistência estudantil na UFPA, Campus de Altamira. Revista Exitus, v. 9, n. 3, p. 87-115, 2019. Disponível em:

http://www.ufopa.edu.br/portaldeperiodicos/index.php/revistaexitus/article/ view/931 Acesso em: 10 fev. 2020.

XAVIER SILVA, A. R. A materialização do Programa Nacional de Assistência Estudantil na Universidade Federal do Acre: texto, contexto, processos e práticas Dissertação (Mestrado em Educação). Universidade Federal do Acre - UFAC, 2019.

Recebido em: 29 de março de 2020 Aprovado em: 12 de maio de 2020 Publicado em: 21 de julho de 2020 